\title{
Engendering maternal and child health care services in cross river state health agenda in Nigeria: what worked well in a pilot study
}

Kabiru K. Salami ${ }^{*}$ and David O. Akeju²

*Correspondence: kabsalami@yahoo.co.uk

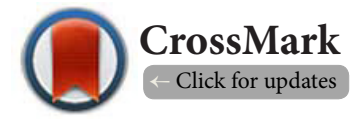

'Department of Sociology, University of Ibadan, Nigeria.

${ }^{2}$ Department of Sociology, University of Lagos, Nigeria.

\begin{abstract}
Objective: This study assessed the performance of maternal and child health (MCH) services launched between 2009 and 2012, as a pilot program in two local government areas (LGAs) of Cross River State, Nigeria.

Design: Interventions included: rebuilding existing staff capacity; regular supply of vaccines; improved work environment; enhancing community participation in promotion of $\mathrm{MCH}$ services; and strengthening the staff size by recruiting medical officers for supervision of activities and prompt response to complications.

Methods: Through a 30 cluster sampling technique, a house-to-house survey approach was adopted to sample three categories of participants from 1,171 households at baseline and compare with performance of respondents from 1,299 households at end-line.

Results: Results showed a $2.3 \%$ (from $11.2 \%$ to $8.9 \%$ ) decrease in under-five mortality. Also, an $8 \%$ decrease in immunization rate was observed during the intervention year. There was significant improvement in the population of women who delivered babies at a health centre at baseline (30.7\%) relative to the population who delivered during the intervention year (45.2\%); showing a $15 \%$ impact attributable to the intervention programme. Results also show that the prevalence of diarrhea and malaria among under-fives reduced from $49 \%$ to $45 \%$ and $62.2 \%$ to $52.5 \%$ respectively. Primary health centre recorded the most increase in patronage from $21.9 \%$ at baseline to $40.7 \%$ at end-line.
\end{abstract}

Conclusion: These results suggest the possibility of high rate of success for sustainable Development Goals (SDGs) pertaining to MCH in Nigeria if all stakeholders across the 774 LGAs provide the minimum inputs required to enhance the Primary Health Care (PHC) services.

Keywords: Service trust, community involvement, maternal health, child health, health care services, Nigeria

\section{Introduction}

Over the past two decades, maternal and child health has attracted unprecedented attention especially in developing countries where the burden of maternal and child mortality is very high. Although maternal mortality in Nigeria has consistently witnessed a decline in the past few years, it is still very high at 560 per 100,000 [1] despite concerted efforts aimed at stemming it. Similarly, infant and child mortality rates still remain unacceptably high at 69 per 1,000 population of live birth [2]. Meanwhile, improving the health conditions of people, most especially reducing maternal and child mortality, through the Primary Health Care (PHC) system is a major strategy in the attainment of the highest possible level of health by all- a core objective of the World Health Organization [3]. To achieve the 'Health for All' objective, most countries in the world, developing countries inclusive, established a system that could turn the 
Salami et al. Research Journal of Women's Health 2017,

dangerous tide. This is underscored by the dramatic changes experienced during the last four decades of the 20th Century which greatly influenced the repositioning of government's role in health as well as other social sectors [3-6]. The Nigerian $\mathrm{PHC}$ system, which is one of the three-tier systems, has the main thrust of bringing health care - the main responsibility of the government, to the door steps of Nigerians. These efforts have achieved some gains over the last decade with annual maternal death worldwide now closing towards half of the 1990 estimate [7-8]. Much of these gains are attributable to efforts focused towards specific illnesses responsible for the high rate of maternal mortality globally. However, notwithstanding these gains, the sub-Saharan Africa has not benefited much $[\mathbf{5}, \mathbf{9}]$, as at the timeline year set by the Millennium Development Goals (MDGs) [10].

In Nigeria, PHC also continues to be the cornerstone of health development. In view of the MDGs, there was need to revitalize the system to achieve the target. Towards that revitalization, health service management was decentralized at the three levels. In addition, States came up with Health Management Boards, responsible for direct service delivery while the Ministry of health focuses on policy formulation, standard setting and monitoring and evaluation [11]. In spite of these efforts, the health status of the country continues to slide. For instance, in the year 2000, Nigeria's overall health system performance was ranked by the World Health Organization $187^{\text {th }}$ among the 191 member states [12]. More than a decade after, only a slight improvement has been recorded [11]. In addition, only $53.0 \%$ of Nigerian children aged 12-23 months were fully immunized in 2010 [13]. These were partly attributed to poorly performing and ineffective health personnel providing ineffective primary health care services [14].

The state of Nigeria's health care delivery systems and services was largely attributed to low government commitment to developing the PHC services in the country [15]. In 1988, the Nigerian government adopted the National Health Policy and Strategy to achieve health for all Nigerians and established $\mathrm{PHC}$ as an integral part of the national health system and a priority for national development. The importance of PHC system was reinforced by the establishment of the National Health and Development Agency in 1992 to provide technical support and translation of policy to feasible strategies. There was also in 1988 National Policy on Population for Development, Unity, Progress and Self Reliance to address family planning issue (though it was not enforced), not for maternal mortality reduction [16].

Against this background, this study sought to provide an assessment of a pilot programme geared towards enhancing health care service delivery in Cross River State, Nigeria. The main objective of the programme studied was to develop through community participation a strengthened $\mathrm{PHC}$ system at grass-root level. Specifically, intervention programme was aimed at establishing a functional network for safe motherhood; to provide for infants and children appropriate promo- tive, preventive and curative health care services including immunization, and to evaluate the impact of the intervention programme using some key performance indicators.

\section{Materials and methods \\ Study area}

This study was carried out in Bekwarra and Obubra LGAs in Cross River State. Bekwarra LGA was carved out of Ogoja LGA of Cross River State and shares boundaries with Ogoja and Boki in the south, Obudu LGA in the east and inter State boundary with Vandiekiya LGA of Benue State in the North. It occupies a total landmass of about 345 square $\mathrm{km}$ and has a projected population of 115,298 people [17]. In all, there are 36 health facilities in Bekwarra LGA. The second LGA - Obubra - is in the Central Senatorial District of Cross River State. Being one of the oldest LGAs in the country, established as a British Colonial District, it has one of the largest land mass in the area. Its jurisdiction extended to parts of present day Biase, Akamkpa, Abi and Yakurr, and parts of Ogoja and Ikom LGAs in Cross River State. Obubra has an area of $1,115 \mathrm{~km}^{2}$ and a population of 172,444 [17]. Both LGAs had Primary health care structures that date back to colonial era. General lifestyle is largely determined by the prevailing environmental conditions.

\section{Intervention activities}

Intervention activities hinged on public-private partnership collaboration between the government of Cross River State and Tulsi Chanrai Foundation, a Non-governmental Organization. The activities, which were implemented across the communities, focused on essential services required for effective delivery of maternal and child healthcare services. Health workers were recruited and trained in the two LGAs in addition to those that existed before the programme. Training which centred on maternal health care services as contained in the programme's Standing Order was carried out for 6 weeks. Medical officers were recruited for each of the LGAs to supervise maternal health care services in all the communities of the two LGAs. Health centres were also renovated and facilities in the centres were upgraded. Each health facility was also provided with a power-generating plant to power the cold chain for safe keeping of vaccines. Each LGA was equipped with ambulance and Hi-Lux jeep for the purpose of surveillance and for rapid response to obstetric emergencies. Community members were involved in most of the intervention activities. For instance, community health committee were set up in most communities to oversee some of the activities of the health facilities, to support in mobilizing their people towards utilizing the facilities and even in the monitoring and clearing of the surroundings of facilities.

\section{Sampling procedure}

The survey was based on the WHO 30-cluster method which is similar to the EPI cluster sampling method designed to estimate vaccination status among children. Using the cluster 
sampling method, all communities within the LGA were listed based on their population size and sample of communities was thereafter performed in line with probability proportional to size. Consideration was given to household size and number of villages within each local government. All communities in each LGA constituted the sampling frame from which 30 communities were selected. Each community represents a cluster within which household survey was carried out. A household was defined as comprising a father, a mother, their children and anyone residing with them and considered as members of the household. In each community, a minimum of 10 households were sampled randomly, and where the 10 households benchmark could not be attained, households in the next village were surveyed until the required benchmark was reached. A pre-coded and well-validated survey instrument was used to collect information from four categories of individuals. From each household, information on infant children, children more than 1 year old but not more than 2 years, children under-five years, and recently pregnant women, were collected. In a situation where either a mother or guardian was not available to provide information about a child, interviewers made effort to check back at least one more time before moving to other village within the cluster.

Overall, field exercise was supervised by the investigators while returned copies of the questionnaire were checked and edited daily by the field supervisors. All returned copies of the questionnaire were coded and processed using software for data entry and analysis. Data were thoroughly cleaned and consistency check carried out before they were analysed. Descriptive and bivariate analyses were conducted to categorise and present the results.

\section{Findings}

Data for this study were generated from a total of 2,470 households, out of which 1,171 households were surveyed at baseline and 1,299 households at end-line. In all, results showed that 458 (39\% of households at baseline) and 598 (54\% of households at end-line) households had children whose ages were 0-11 months. Households with children between ages 12-23 months constituted $49.1 \%$ ( $n=597$ households at baseline) and $42.3 \%$ ( $n=550$ households at end-line) of the surveyed households (Graph 1).

Children who were under the age of five were found in 796 (67.8\% at baseline) and 762 (58.7\% at end-line) of the households surveyed. Recently-pregnant mothers were found present in 458 (39.0\% baseline) and 577 (44.4\% end-line) of all the households surveyed. The Graph 1 describes the four categories of people sampled in each household. The results are presented for each of these categories.

\section{Utilization of maternal health services}

The importance of antenatal care (ANC) in effective delivery of maternal and child care has been emphasized. However, utilization of health services in Nigeria is significantly moderated by cost [18]. Findings in this study compared the baseline and end-line results of women who got registered for ANC. During the baseline, $413(88.1 \%)$ of the mothers reportedly booked for ANC and increased to 505 (86.9\%) mothers at the intervention year. Conspicuously, the results here describe the ANC-seeking behaviour of mothers at pregnancy to be of nearly equal proportion during the baseline and the intervention periods. This finding posits that the intervention did not significantly influence enrollment for antenatal care relative to total population of pregnant women. It also indicates that the status of maternal health is not as a result of poor enrollment for antenatal care, but of the ability to follow-through with the care process.

\section{Routine immunization and medications}

Data on routine immunization and medication for pregnant women were collected using information on antenatal care records found on the antenatal card of the women. Results

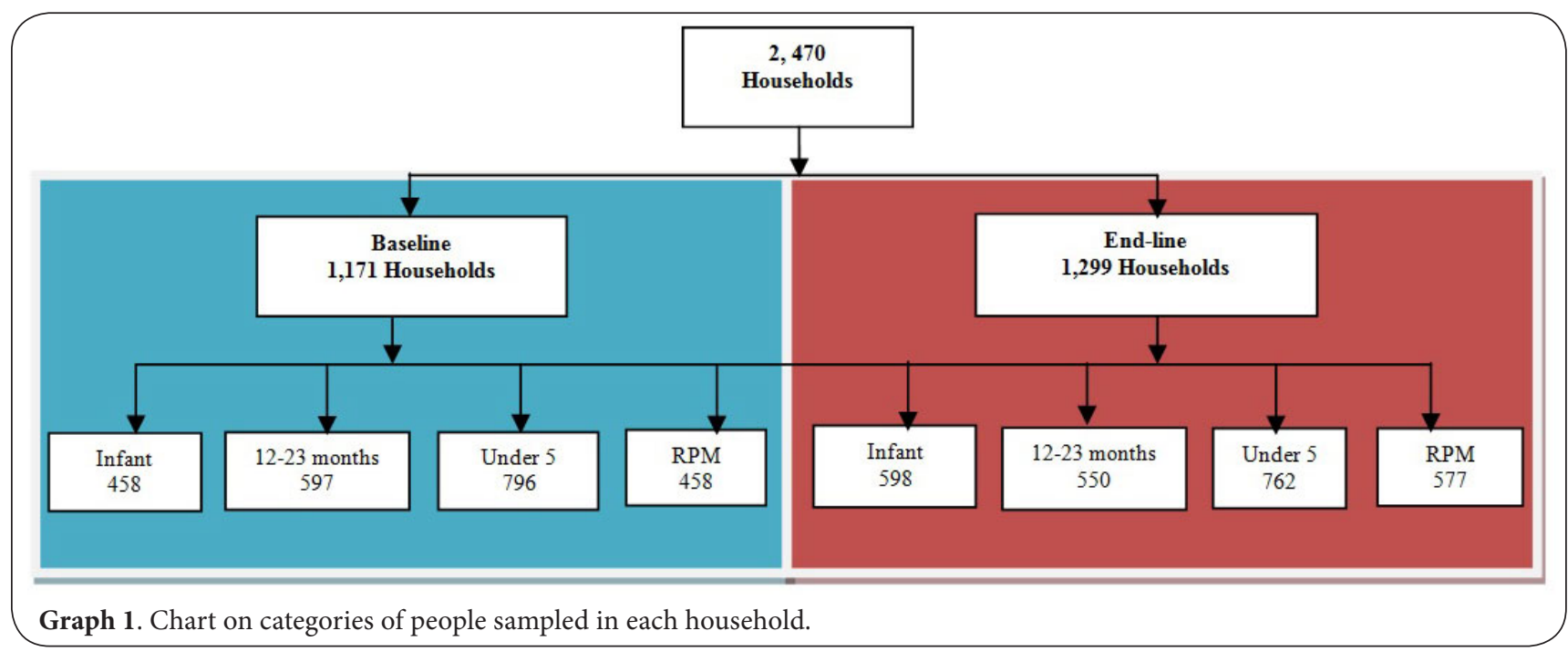


derived from routine immunization and medications show a decline in the overall TT rates at the end-line with the exception of TT3 where a huge increase was observed after the intervention. Comparing the TT immunization performance of mothers, Figure $1 \mathrm{a}$ shows that a large proportion of mothers $(91.4 \%)$ received the first dose of TT during the baseline, which however dropped to $78.5 \%$ after the intervention. While the number of those who received TT2 at the baseline remained constant at $91.5 \%$, there was a $15.2 \%$ decline in the number of women who received TT2 after the intervention.

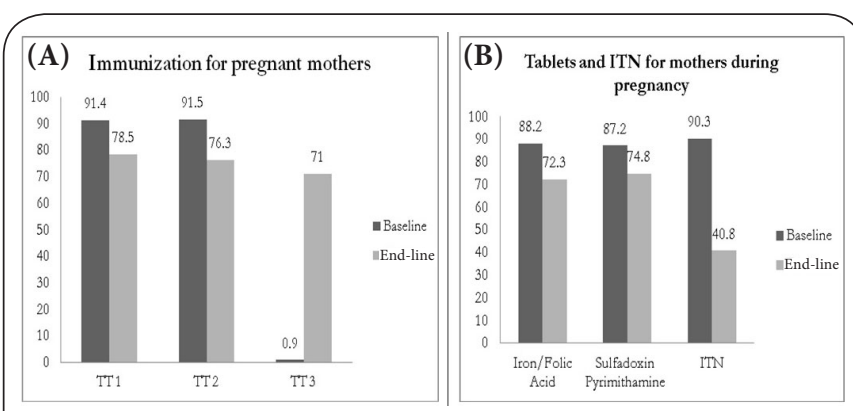

Figure 1. Immunizations and Medication for Pregnant Women.

(A). Immunization Patterns for Pregnant Women.

(B). Drug Administration to Pregnant Women.

Comparatively, while coverage rate after the intervention is lower than what was reported for the baseline, there was a relatively stable proportion of population that took the TT1TT3. For instance, the proportion of women who had the third dose significantly increased from $0.9 \%$ at the baseline to $71.0 \%$ after the intervention. This increase could be attributed to consistent health education and enlightenment campaign by health workers who were deployed to the community to health-educate pregnant women on the importance of the third dose of TT immunization.

The observed drop in the coverage during the first and second doses of TT immunization was as a result of low supply of vaccines after the intervention. The low supply of commodities generally affected drug administration at all levels of antenatal care services. For instance, in the administration of Folic Acid, Sulfadoxin Pyrimithamine (SP), and the supply of ITN, there was a general decline in the proportion of women who received during the baseline and those after the intervention. This is represented on Figure $1 \mathbf{b}$ which shows $15.3 \%$ decline in the proportion of women who received Folic Acid after the intervention. The same was observed for the administration of SP which recorded a decrease of $12.4 \%$ after the intervention.

There was a drastic reduction in the proportion of women who received ITN at the end-line. While $326(90.3 \%)$ of the mothers reportedly received ITN at health centre during the baseline exercise, only 135 (40.8\%) of the women reportedly received ITN after the intervention year.

\section{Sources of pregnancy care and place of delivery}

The study sought to know the sources from which women received care during pregnancy and the places where they delivered their babies. During the baseline, most (88.4\%) mothers reportedly booked for ANC at Health Centre. However, results on place of delivery show significant increase in the number of women who delivered at health centre during intervention $(45.2 \%)$ relative to the women who delivered at health centre during the baseline $(n=168 ; 36.6 \%)$ survey. Although the population of those who delivered at health center was still lower at end-line $(n=261 ; 45.2 \%)$ than those registered $(n=394 ; 78 \%)$, the result still shows a $15 \%$ impact made by the intervention programme.

Table 1 presents results on types of delivery personnel who attended to the pregnant women during delivery. At baseline, about one-third (34.6\%) of the respondents were attended to by Nurse/Midwife, nine (2.0\%) women were attended to by medical doctors and seven (1.5\%) were attended to by trained TBAs. Three $(0.7 \%)$ pregnant women were reportedly delivered by untrained TBAs. More than half, 282 (61.3\%) mothers reported that other women attended to their delivery. The end-line results which show that 33 (5.7\%) pregnant

Table 1. Attendants at the delivery for pregnant women.

\begin{tabular}{lllll}
\hline Delivery attended by & \multicolumn{2}{c}{ Baseline } & \multicolumn{3}{c}{ End-line } \\
\cline { 2 - 5 } & Number & \% & Number & $\%$ \\
\hline Doctor & 9 & 2.0 & 33 & 5.7 \\
Nurse/Midwife & 159 & 34.6 & 289 & 50.0 \\
TBA Trained & 7 & 1.5 & 40 & 6.9 \\
TBA not trained (Church) & 3 & 0.7 & 24 & 4.2 \\
Other women & 282 & 61.3 & 178 & 30.8 \\
Nobody (Self delivery) & -- & -- & 14 & 2.4 \\
Total & 460 & 100.0 & 578 & 100.0 \\
\hline
\end{tabular}

women were delivered by doctors and another 289 (50\%) pregnant women delivered by nurse/midwife at health facilities give an increase of $3.7 \%$ and $15.4 \%$ best practices in baby delivery and attendants respectively. The number of pregnant women attended to by other women decreased drastically from $61.3 \%(n=282)$ to $30.8 \%(n=178)$; implying a $50 \%$ decrease. However, the number of women who patronized TBAs increased.

\section{Impact on child and maternal mortality}

Figure 2 compares pre and post intervention results on mortality and shows a decrease in infant mortality from $12.5 \%$ during the baseline to $8.3 \%$ at end-line, accounting for a reduction of $4.2 \%$ in infant mortality.

Similarly, there was a reduction in under-five mortality from $11.2 \%$ to $8.9 \%$-a $2.3 \%$ decline in under-five mortality. The overall comparison of infant and under-five mortality rate 


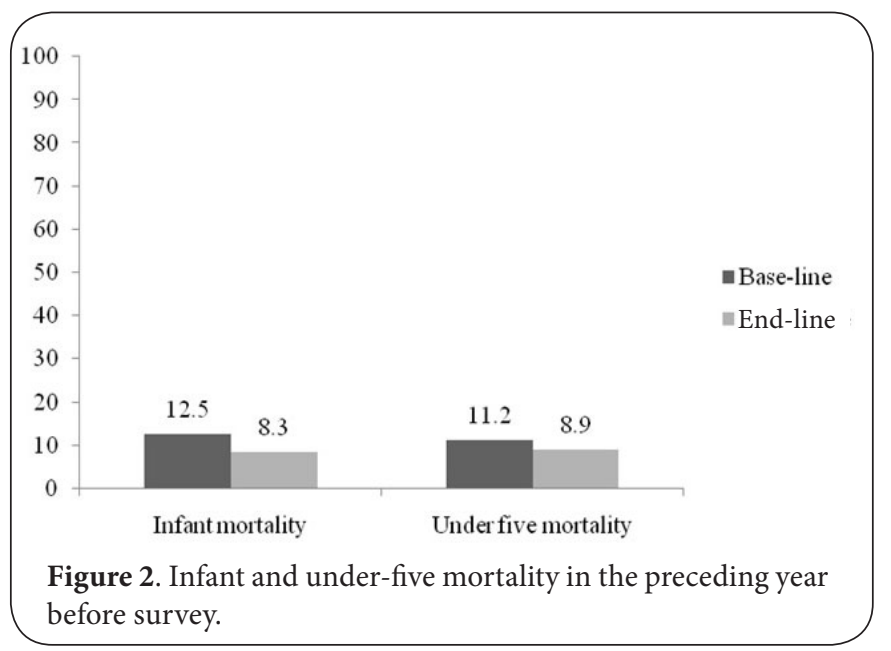

indicates a greater impact recorded among infant children than among under-five children. Table 2 reveals that there was a slight impact made by the intervention directed at under-five children as mortality rate at the baseline (56/1000) decreased to 54/1000 after the intervention. Similarly, results on maternal mortality show a significant improvement with a decrease from $66(5.6 \%)$ or $560 / 10,000$ before intervention to $6(0.5 \%)$ or $50 / 10,000$ after intervention.

Table 2. Calculated maternal, infant and under-five death rates.

\begin{tabular}{|c|c|c|c|c|}
\hline \multirow{2}{*}{$\begin{array}{l}\text { Mortality } \\
\text { rates of sub- } \\
\text { population }\end{array}$} & \multicolumn{2}{|l|}{ Baseline } & \multicolumn{2}{|l|}{ End-line } \\
\hline & $\begin{array}{l}\text { Population } \\
\text { size }\end{array}$ & $\begin{array}{l}\text { Calculated } \\
\text { Death } \\
\text { Rate }\end{array}$ & $\begin{array}{l}\text { Population } \\
\text { size }\end{array}$ & $\begin{array}{l}\text { Calculated } \\
\text { Death } \\
\text { Rate }\end{array}$ \\
\hline $\begin{array}{l}\text { Deaths Rates } \\
<5 \text { past year }\end{array}$ & 1456 & $56 / 1000$ & 1466 & $54 / 1000$ \\
\hline $\begin{array}{l}\text { Infant deaths } \\
\text { rates past year }\end{array}$ & 1362 & $59 / 1000$ & 1766 & $57 / 1000$ \\
\hline $\begin{array}{l}\text { Maternal } \\
\text { mortality rates }\end{array}$ & 1119 & $56 / 1000$ & 1437 & $5 / 1000$ \\
\hline
\end{tabular}

The decline in mortality rate was achieved despite poor performance in routine immunization for both childhood diseases and for pregnant women. The possible factors responsible for the decline are the intervention activities in place. These included the enhancement of facility with necessary equipment for delivery of essential maternal health services. Of note is the supply of ambulance for rapid response to emergency obstetric complications, particularly in hard-to-reach communities.

Immunization coverage for children 12-23 months Immunization coverage of children 12-23 months was reviewed. The study sourced for immunization cards from the mothers or simply requested direct information from the mother to ascertain: if the child got all the necessary vaccines; the age (in month) at which the vaccines were taken; mode of application (e.g., oral or intravenous) of the vaccine; and location / part of the body where the vaccine was applied. At baseline, out of the 390 children who received BCG vaccination at birth, a large majority, 385 (98.7\%) of them received it at health centre, contrary to $423(86.7 \%)$ children who did so at the end-line survey. Similarly, before intervention, a significantly high number of children received DPT1 (98.3\%), DPT2 (98.3\%), and DPT3 (98.6\%) at health centre. However, the end-line data showed a decline in the number of children who received DPT1 (86.4\%), DPT2 (86.7\%) and DPT3 $(87.6 \%)$ at health centre. The same trend was observed among children who received OPV1 (95.3\%), OPV2 (96.4\%), and OPV3 (95.5\%) at health centre before intervention. After intervention, the performance percentage dropped to $87.1 \%$ (OPV1), $85.6 \%$ (OPV2), and $86.3 \%$ (OPV3). A general decline in the rate of immunized children during the intervention was observed as shown in Figure 3.

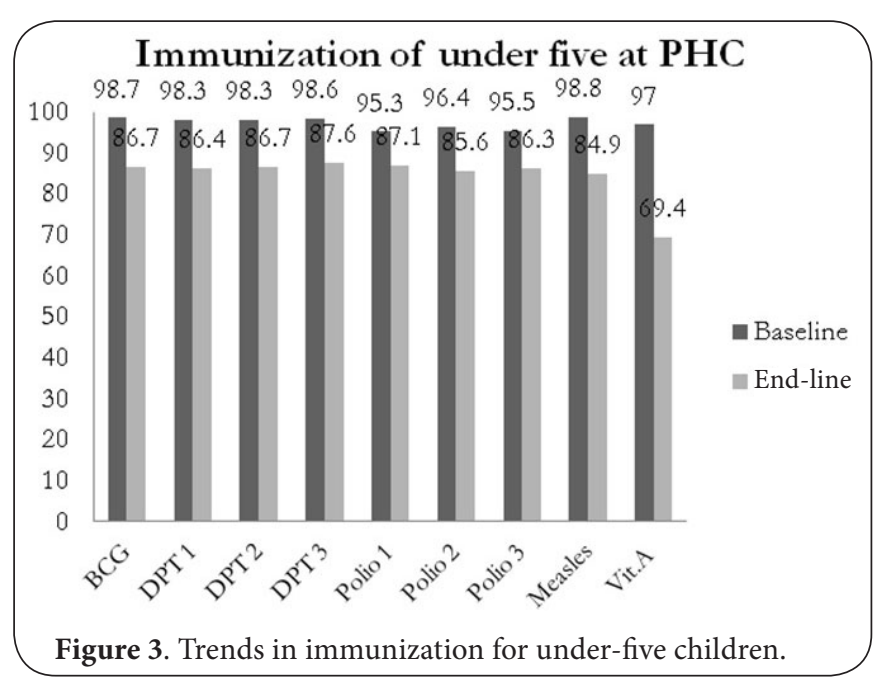

Baseline result of measles vaccine received at health centre decreased from $98.8 \%$ to $84.9 \%$. The reduction in Vitamin A supplement provided for children at health centre was also drastic during the intervention phase. While post intervention results showed that $69.4 \%$ children received Vitamin A, $97.0 \%$ children were shown to have received it at the baseline. The pattern of children immunization performance observed underscored the need to understand the factors responsible for the low coverage reported during the intervention. Hence, a review of commodity supply to the two LGAs prior to and during the intervention periods was carried out through posthoc interviews. The review results indicated a high shortage of supply of vaccines in the state during the intervention. Post-hoc Interviews with health workers in charge of health facilities in the two LGAs validated a great shortfall in the supply of vaccines in the years that preceded the intervention 
Salami et al. Research Journal of Women's Health 2017,

http://www.hoajonline.com/journals/pdf/2054-9865-4-3.pdf

period. According to a Chief Nursing Officer (CNO), "There was a general problem of stock. We did not have sufficient vaccine for children. We were in shortage of supply to meet up with demand, hence many children were turned back home without being immunized with vaccine". Another CNO also expressed an unhappy experience: "We kept sending mothers back and encouraged them to return on other days just to check in case we have vaccines to give them. The truth is that the vaccine supply for those years shortfall the demand." Clearly, the role of commodity supply in meeting the health needs of women and children was indispensable. Possibility of disparities in supply-side for vaccines was explained in terms of the individual state capacity to determine its own healthcare delivery system and its relative allocation of financial resources as it deems fit, without input from the federal government [19]. Except that shortage of vaccines was a major issue at intervention, shortage of human resources to coordinate commodity-supply at all levels of government was also reportedly insufficient for service delivery [19].

The immunization status of the children aged 12-23 months was classified as fully immunized, partially immunized or non-immunized both at baseline $(n=469)$ and intervention $(n=568)$. At baseline, 223 (47.5\%) children were fully immunized compared to 252 (44.4\%) fully immunized children at end-line. Though, more $(n=246 ; 52.5 \%)$ children were not immunized at all at baseline, the poor performance of "nonimmunized" dipped down drastically at end-line ( $n=93 ; 16.4 \%)$ indicating a good performance overall, at end-line. Significantly, the study showed a general improvement in the immunization rates in the two LGAs at end-line. This is attributable to the interventions in the two LGAs. However, better coverage would have been achieved but for the poor commodity supply recorded during the intervention period. The intervention period recorded 223 (39.2\%) children as partially immunized at end-line. Against the background of poor vaccine supply, the high number of children who were partially immunized during the intervention implies that the interest of most mothers to willfully immunize their children fully was dashed due to shortage of vaccine supply.

\section{Under-five children's illness experience two weeks be- fore survey}

The experience of mothers about childhood diarrhoea, malaria and acute respiratory infections (ARI) within the past two weeks before the survey was sought and documented as shown in Figure $4 a$. The incidence of diarrhea was $49 \%$ at the baseline, indicating that five in every 10 under-five children had diarrhea cases two weeks prior to the survey. Relatively, a slight decrease (45\%) in cases of diarrhea was reported by the end-line survey. Similarly, the prevalence of malaria among the same population reduced from $62.2 \%$ (baseline) to $52.5 \%$ (end-line). However, there was an upsurge in the number of children who suffered from ARI during the intervention (54\%) compared to baseline (29.6\%). Results also show an increase

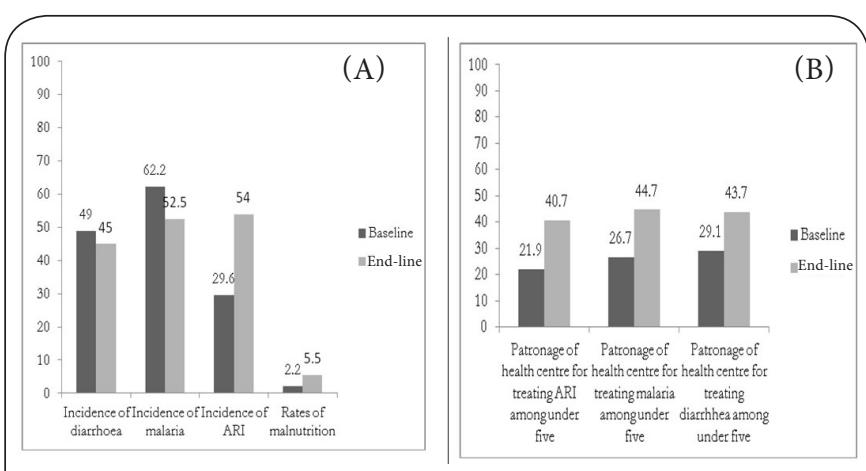

Figure 4. Childhood illnesses and sources of treatment. (A). Incidence of childhood illnesses.

(B). Sources of treatment for Diarrhea, Malaria and ARI.

in the number of malnourished children from 2.2\% (baseline) to $5.5 \%$ (end-line) in both LGAs.

The study also documented the treatment outcome for childhood illnesses. The proportion of mothers who treated their children's diarrhea cases at health centres increased from $29.1 \%$ at baseline to $43.7 \%$ at end-line. Unfortunately, those who treated malaria at home recorded a slight increase from $8.3 \%$ during the baseline to $10.2 \%$ after the intervention. The proportion of children who received treatment for malaria at the health centre increased significantly from $26.7 \%$ to $44.7 \%$.

Likewise the proportion of mothers who treated their children at health centre for ARI also increased from $21.9 \%$ at baseline to $40.7 \%$ after intervention as shown in Figure $\mathbf{4 b}$. Record of home visits by the health workers also almost double from $44.5 \%$ at baseline to $80.3 \%$ at end-line.

\section{Discussion and conclusion}

Contrary to the low patronage of pregnancy-delivery services even by women who registered in a facility [20-22], findings in this study has proved that patronage of health center for delivery by pregnant women could be increased, as $15 \%$ increase was recorded in this study within 12 months of intervention. Specifically, the result in this study shows that one major reason why women failed to patronize health facility was the lack of confidence in healthcare system. This result is important against the backdrop of previous findings that implicated cost, distance, cultural values and education as determinants of patronage [23-24]. Thus, this study highlights the importance of confidence-building as a core component for achieving improved patronage of primary health care services and maternal and child survival. High level of commitment by the government, community participation and other stakeholders can actually boost the confidence of women in utilization of healthcare services.

This study revealed that registration for ANC was not significantly affected by the intervention programme. Pregnant women are expected to have full ANC attendance while at the same time are expected to be attended to by qualified 
health personnel at health centers. Surprisingly, this study has further showed that antenatal registration is not a major maternal health problem since the intervention programme could not significantly increase the number of women who registered during the baseline and end-line periods. Rather, the problem lies in the follow-up role of pregnant women which is the main responsibility of community health workers. For some reasons, after registration, some women may not visit the health centre again until they experienced complication. This is the gap which this intervention study has successfully covered by recruiting and training community health workers and deploying them to the community. Majority of the women who registered for antenatal care were able to follow through the process till delivery. With early, consistent and appropriate antenatal care-seeking behaviour, the burden of maternal and child mortality in sub-Saharan Africa is expected to reduce significantly. For instance, the strength of health centers for intervention against pre-eclampsia and some foetal problems, and how same facilities could contribute to safe delivery have been reported [25]. Such benefit was expected to occur during the intervention if clients had patronized as proposed.

While maternal mortality decreased significantly from $560 / 10,000$ to $50 / 1,0000$ women of reproductive age, immunization against childhood killer diseases suffered a setback. The significant success in the reduction of maternal mortality reveals the marked difference that could be achieved when health personnel are provided with necessary equipment to perform their responsibilities. Rapid response of medical team to emergency obstetric cases, especially in areas that are hard to reach, can enhance medical operations that may have farreaching effect on health outcomes. Also, the shortfall supply of vaccines recorded during the intervention influenced the rate of full or partial immunization taken by the children. This finding points out the role of government and other agencies in the supply chain of health commodities. Eboreime, Abimbola and Bozzani [19] observed that the weakest links in Nigeria's immunization system are local governments, which are responsible for the delivery of PHC services. This weakness is largely due to poor financing and poor foresight of career health planners in vaccines commodity-demand at the local government. While rehabilitation of health facilities is a necessary condition, it is not sufficient to boost the quality of maternal and child health. Therefore, all agencies involved in the supply and administration of chain of drugs and other maternal and child health related services and products are relevant. Hence, the process of procurement, storage, supply and distribution of drugs and other commodities should be assessed with the aim of strengthening its capacity to deliver promptly.

The need to enhance the services of health centers in rural communities by building staff capacity, and by engaging community to increase patronage is a lesson learnt in this study. The community has the potential for attracting the interest of its members and for encouraging patronage. With such intervention in place, more women are likely to patronize qualified health care personnel at government health centres and hospitals when appropriate governance mechanism and political commitment are in place. Sadly, most primary and secondary health facilities in Nigeria are understaffed; leading to unprofessional practices such as "MAN hour" - a situation where health professionals work in the Morning, Afternoon, and Night in a single shift. This too, in most cases, leads to task shifting among senior and junior health personnel, even when the skills of junior health personnel are incompatible with the task being shifted. As such, the lack of potential and adequate health staff could worsen the existing constraint in human resource both for antenatal and delivery care provision. This burden is likely to be shared by other secondary level hospitals with limited health personnel. In the light of this, more health personnel will be needed at health facilities.

Results from this study provide the evidence that Nigeria could achieve set targets on health care delivery and disease control if all stakeholders across the 774 local government areas provide the minimum inputs required to enhance the PHC facilities. Performance in the immunization at both baseline and end-line has an implication in the determination of lead time for requesting the supplies of vaccines. This indicates the role of commodity supply in meeting the health needs of women and children [19]. The process, channels and logistics involved in the distribution and supply of vaccines must be well strengthened in order to ensure steady commodity supply to health centers where they are needed. The lead time for requesting commodities should also be monitored by the officers in charge to reduce or eliminate the gap that could emerge in the process of requisition.

The Immunization status of the children (aged 12-23 months) was classified as fully immunized, partially immunized or nonimmunized both at baseline $(n=469)$ and intervention $(n=568)$. Significantly, the study showed a general improvement in the immunization rates in the two LGAs at end-line. This is attributable to the interventions in the two LGAs. However, more coverage would have been achieved but for the poor commodity supply during the intervention year.

Even though the programme lapses may not be attributable to it, the high level of malnourished children recorded during the intervention should be addressed. The malnutrition level may determine the poverty level of the child's parents and their relative acceptance of health education offered to them at the intervention. While documentation of malnourished children was based on simple observation of certain features in children, observation done simultaneously with recording information during survey could result in role conflict for field staff and can affect accurate documentation on the field. Future training should also emphasize observable factors. Furthermore, emphasis should not be placed on parental attention or the program lapses alone but also on the differences in weather during the baseline and the end-line. In addition, poverty is 
Salami et al. Research Journal of Women's Health 2017,

http://www.hoajonline.com/journals/pdf/2054-9865-4-3.pdf

highly endemic in the two LGAs involved in this study; hence the gradual and consistent slide into poverty is affecting many homes, especially in the study sites where it was difficult to earn a living. Since maternal and child care were the main interest of the program, it was not in the program protocol to cater for the child's feeding patterns.

\section{Competing interests}

The authors declare that they have no competing interests.

Authors' contributions

\begin{tabular}{|l|c|c|}
\hline Authors' contributions & KKS & DOA \\
\hline Research concept and design & $\checkmark$ & $\checkmark$ \\
\hline Collection and/or assembly of data & $\checkmark$ & $\checkmark$ \\
\hline Data analysis and interpretation & $\checkmark$ & $\checkmark$ \\
\hline Writing the article & $\checkmark$ & $\checkmark$ \\
\hline Critical revision of the article & $\checkmark$ & $\checkmark$ \\
\hline Final approval of article & $\checkmark$ & $\checkmark$ \\
\hline Statistical analysis & $\checkmark$ & $\checkmark$ \\
\hline
\end{tabular}

Acknowledgement

The respondents in this study are appreciated for giving their time and attention to participate. Dr Paul Kandasamy - the Director Primary Health Care, Tulsi Chanrai Foundation, Nigeria, is also appreciated for the technical and logistic supports given to us during the study.

\section{Publication history}

Editor: Erich Cosmi, University of Padua, Italy.

Received: 23-Dec-2016 Final Revised: 15-Feb-2017

Accepted: 12-Mar-2017 Published: 22-Mar-2017

\section{References}

1. WHO, UNICEF, UNFPA. The World Bank and the United Nations Population Division (2014) Trends in Maternal Mortality: 1990 to 2013 ISBN 978924150722 6. @ World Health Organization. 2014. | Website

2. Population Reference Burueau (PRB) (2014). 2014 World Population Data Sheet Data prepared by PRB demographers Carl Haub and Toshiko Kaneda. Population Reference Bureau. 2014.

3. WHO (1978) Primary Health Care: Declaration of Alma-Ata 1978. Report of the International Conference on Primary Health Care. AlmaAta, USSR, 6-12 September. Jointly sponsored by the World Health Organisation and the United Nations Children's Fund. 1978; 1-80. | Pdf

4. WHO. The Algiers Declaration: Narrowing the knowledge gap to improve Africa's health. Ministerial Conference on Research for Health in the African Region. 2009. I Website

5. WHO, UNICEF, UNFPA and the World Bank. Trends in Maternal Mortality: 1990-2010. Geneva: WHO. 2012.

6. Hogan MC, Foreman KJ, Naghavi M, Ahn SY, Wang M, Makela SM, Lopez AD, Lozano R and Murray CJ. Maternal mortality for 181 countries, 1980-2008: a systematic analysis of progress towards Millennium Development Goal 5. Lancet. 2010; 375:1609-23. | Article | PubMed

7. Lozano R, Wang H, Foreman KJ, Rajaratnam JK, Naghavi M, Marcus JR, Dwyer-Lindgren L, Lofgren KT, Phillips D, Atkinson C, Lopez AD and Murray CJ. Progress towards Millennium Development Goals 4 and 5 on maternal and child mortality: an updated systematic analysis. Lancet. 2011; 378:1139-65. | Article | PubMed

8. Fapohunda BM and Orobaton NG. When women deliver with no one present in Nigeria: who, what, where and so what? PLoS One. 2013; 8:e69569. | Article | PubMed Abstract | PubMed FullText

9. Welcome MO. The Nigerian health care system: Need for integrating adequate medical intelligence and surveillance systems. J Pharm Bioallied Sci. 2011; 3:470-8. | Article | PubMed Abstract | PubMed FullText

10. United Nations. The Millennium Development Goals Report. New York: UN. 2010; 1-77. I Website

11. Doctor HV, Findley SE, Ager A, Cometto G, Afenyadu GY, Adamu F and Green $C$. Using community-based research to shape the design and delivery of maternal health services in Northern Nigeria. Reprod Health Matters. 2012; 20:104-12. | Article | PubMed

12. Asuzu MC. The necessity for a health systems reform in Nigeria. Journal of Community Medicine \& Primary Health Care. 2004; 16:1-3. | Pdf

13. National Immunization Coverage Survey (NICS). National Primary Health Care Development Agency (NPHCDA), WHO, UNICEF, DFID, Bill \& Melinda Gates Foundation. Federal Ministry of Health. 2010.

14. Manuwa-Olumide A. Addressing the human resource challenges in primary health care, proceedings of the Nigeria Health Conference, 2009, organized by the Health Reform Foundation of Nigeria (HERFON). 2009; 67-75.

15. Travis P, Bennett S, Haines A, Pang T, Bhutta Z, Hyder AA, Pielemeier NR, Mills $A$ and Evans T. Overcoming health-systems constraints to achieve the Millennium Development Goals. Lancet. 2004; 364:900-6. | Article I PubMed

16. Federal Ministry of Health. The national health policy and strategy to achieve health for all Nigerians. Lagos. 1988.

17. National Population Commission (NPC) Nigeria and ICF Micro (2009). Nigeria Demographic and Health Survey 2008. Abuja. National Population Commission abd ICF Macro. 2009. | Pdf

18. Sambo MN, Abdulrazaq GA, Shamang AF and Ibrahim AA. Household cost of antenatal care and delivery services in a rural community of Kaduna state, northwestern Nigeria. Niger Med J. 2013; 54:87-91. | Article | PubMed Abstract I PubMed FullText

19. Eboreime E, Abimbola $S$ and Bozzani F. Access to Routine Immunization: A Comparative Analysis of Supply-Side Disparities between Northern and Southern Nigeria. PLoS One. 2015; 10:e0144876. | Article | PubMed Abstract | PubMed FullText

20. Stokoe U. Determinants of maternal mortality in the developing world. Aust N Z J Obstet Gynaecol. 1991; 31:8-16. | Article | PubMed

21. Babalola $S$ and Fatusi A. Determinants of use of maternal health services in Nigeria--looking beyond individual and household factors. $B M C$ Pregnancy Childbirth. 2009; 9:43. | Article | PubMed Abstract | PubMed FullText

22. Salami KK and Brieger WR. Service delivery and coverage in primary healthcare in a community-health project in Ibadan, Nigeria. Afr J Prim Health Care Fam Med. 2014; 6:E1-7. | Article | PubMed Abstract | PubMed FullText

23. Adebayo AM and Asuzu MC. Utilisation of a community-based health facility in a low-income urban community in Ibadan, Nigeria. Afr J Prim Health Care Fam Med. 2015; 7. | Article | PubMed Abstract | PubMed FullText

24. Kabir M, lliyasu Z, Abubakar IS and Asani A. Determinants of utilization of antenatal care services in Kumbotso Village, northern Nigeria. Trop Doct. 2005; 35:110-1. | Article | PubMed

25. Osungbade KO and Ige OK. Public health perspectives of preeclampsia in developing countries: implication for health system strengthening. $J$ Pregnancy. 2011; 2011:481095. | Article | PubMed Abstract | PubMed FullText

\section{Citation:}

Salami KK and Akeju DO. Engendering maternal and child health care services in cross river state health agenda in Nigeria: what worked well in a pilot study. Res J Womens Health. 2017; 4:3. http://dx.doi.org/10.7243/2054-9865-4-3 